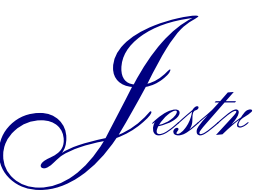

Research Article

\title{
mLearn: A Mobile Learning Platform
}

\author{
C. Lytridis* and A. Tsinakos
}

AETMA Lab, Eastern Macedonia \& Thrace Institute of Technology, Kavala, Greece

Received 24 July 2017; Accepted 18 September 2017

\begin{abstract}
This paper presents the design and implementation of a mobile learning platform developed at the Eastern Macedonia and Thrace Institute of Technology. The platform, named mLearn, aims at providing educators with the tools to organize and conduct educational field trips either outdoors (cities, sites etc.) or indoors (e.g. museums). The system consists of a web portal and a mobile application. During the preparatory stage of the educational field trip, the teachers can upload their relevant educational material through the web portal. During the field trip, the students will have access to these educational resources on-site via the mobile application. For each field trip, the uploaded educational material is catalogued and stored on a server, and will be openly available to the public so that it can be reused in other educational field trips by other teachers and students.
\end{abstract}

Keywords: mobile learning, mobile application, informal learning, user-contributed material, educational resources

\section{Introduction}

The field of mobile learning has attracted much interest in recent years. The introduction of smart portable devices (smartphones and tablets) in the global market, their increasingly wide availability to the general population, and the continuous improvement in their capabilities in terms of processing power and input/output devices, have created new opportunities in learning [1].

As reported in [2], the advantages in using mobile devices as means for providing learning experiences are numerous, including:

- Ease of use: The learner uses a familiar device which is used in a daily basis and he is not required to become accustomed with a new tool, thus removing cognitive load and improving the speed at which learners perform tasks.

- Availability of content at anytime: The learner is not limited to scheduled learning sessions, but instead he freely allocates the time at which he will access the learning materials.

- Portability: While distance education and indeed mobile learning allows access to content at any time, mobile learning also enables access to content literally anywhere since the user always carries his smart mobile device with him. Also, it means that situated learning is possible, at the location where training or support is needed.

- Collaborative learning: the communication capabilities through a wireless network that are inherent on the mobile devices such as instant messages, SMS, voice calls, shared calendars, access to forums etc. are well suited for

\footnotetext{
*E-mail address: Iytridic@teiemt.gr

ISSN: 1791-2377 @ 2017 Eastern Macedonia and Thrace Institute of Technology. All rights reserved. doi:10.25103/jestr.104.11
}

cooperative learning activities and content sharing.

These advantages create the potential for developing educational mobile applications which are either web-based or are native applications for the various mobile platforms. There have already been several studies in the previous years which apply mobile learning in real settings and study its effectiveness, either in the classroom [3], or in fieldwork [4]-[6].

Especially interesting is the latter case where learning takes place on location and is usually assisted by the location awareness capabilities through global positioning systems (GPS) or network-based location acquisition which is embedded in most of the modern smart mobile devices. In this case, the location awareness feature is particularly useful, in that it allows learning to take place on the location of interest (such as in a museum, an archaeological site, or any other place of educational interest), and the information that becomes available at that time is directly related to the physical position of the learner [7], [8].

Other approaches include applications which use Augmented Reality technology, which takes advantage of the location awareness feature of smart mobile devices. In this context, the experience of the learner in a site of cultural interest is enhanced by moving graphics superimposed on the learner's perception of the real world, that both guide him through the site as well as deliver additional information about the site. For example, in [9] an e-learning project using Augmented Reality for cultural heritage education in various landscape units in Spain is presented. Another example of an augmented reality educational platform is ARLearn, which supports training scenarios, serious games based on decision making [10].

Motivated by the aforementioned work in the field of mobile learning and the initial pilot study of integrating mobile learning in a commercial tourist application presented in [11], this paper presents the design and implementation 
of a platform which is being developed at the Advanced Educational Technologies and Mobile Applications Lab (AETMA Lab) at the Eastern Macedonia and Thrace Institute of Technology, that can be used by educators for field trip planning. The building blocks and operation of the mLearn platform are presented and future developments and applications are proposed.

\section{The web portal}

The web portal is accessed using a browser and is used by the teachers to upload the educational material which is to be used during the field trip. Before uploading the material, the teacher must create an educational field trip. Each field trip consists of activities. The software allows for two types of field trip activities: a) outdoors points of interest (POIs) when visiting a city or a historical site and b) indoors items when visiting museums or industrial facilities. For the former case, the educational material is linked to coordinates which correspond to the points of interest. For the latter case, the material is linked to QR codes which correspond to items such as exhibits, artifacts or equipment, depending on the subject of the field trip. It was decided that using QR codes is an appropriate method of tagging the various items since they can be easily generated by free online services. These QR codes can be printed and placed next to the corresponding items prior to the visit, as part of the trip preparation.

\subsection{Field trip creation}

The process of uploading material is straightforward and does not require the user to have any special technical skills or training. The first page of the web portal shows a list of the available field trips and allows the creation of new ones. Fig. 1 is a screenshot of the mLearn platform's front page:

\section{口象吅 mLearn 口再茟}

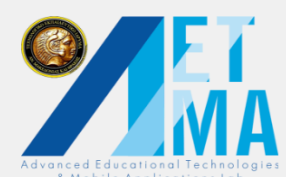

\section{Available field trips}

\begin{tabular}{|l|l|l|l|}
\hline Trip Id & \multicolumn{1}{|c|}{ Title } & Description & Actions \\
\hline 107. & Castle of Kavala & A field trip to the Castle of Kavala \\
\hline 108. & Trip to Philippi & A trip to the archaeological site of Philippoi for 6th grade students \\
\hline
\end{tabular}

\section{Add new field trip}

Fig. 1. mLearn's front page

The teacher can manage the field trips by editing or removing them. Each field trip can be edited or deleted. The selection of a field trip opens a new page which lists the activities assigned to the particular field trip. The activities can be a mix of QR and POI items. An example field trip page with activities of POI type are shown in Fig. 2.

\section{口й mLearn 回再昰}

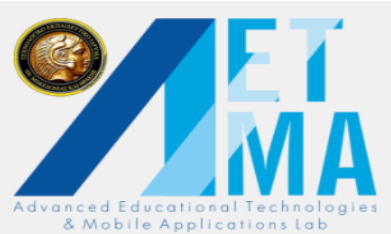

\section{Trip to Philippi}

\begin{tabular}{|l|l|l|l|}
\hline Item id & \multicolumn{1}{|c|}{ Item } & \multicolumn{1}{|c|}{ Type } & \multicolumn{1}{|c|}{ Actions } \\
\hline 194. & Basilica of Paul & Point of interest & Edit item I Delete item \\
\hline 197. & Ancient Theater of Philippi & Point of interest & Edit item I Delete item \\
\hline 198. & Ancient Market & Point of interest & Edit item I Delete item \\
\hline
\end{tabular}

\section{Add new item}

Fig. 2. Field trip page 
In this page the teacher can add, edit or delete activities. For QR activities in particular, the teacher can view and print the corresponding QR tag.

The teacher can enter the following information regarding the item:

- The description of the item

- A related webpage for further information (such as the corresponding Wikipedia entry)

- The filename that contains the teacher-prepared educational material for the activity

- $\quad$ The type of activity (QR or POI)

- A location from the map in the case of a POI activity.

The following figure demonstrates the ease of creating a geolocation item within a field trip.

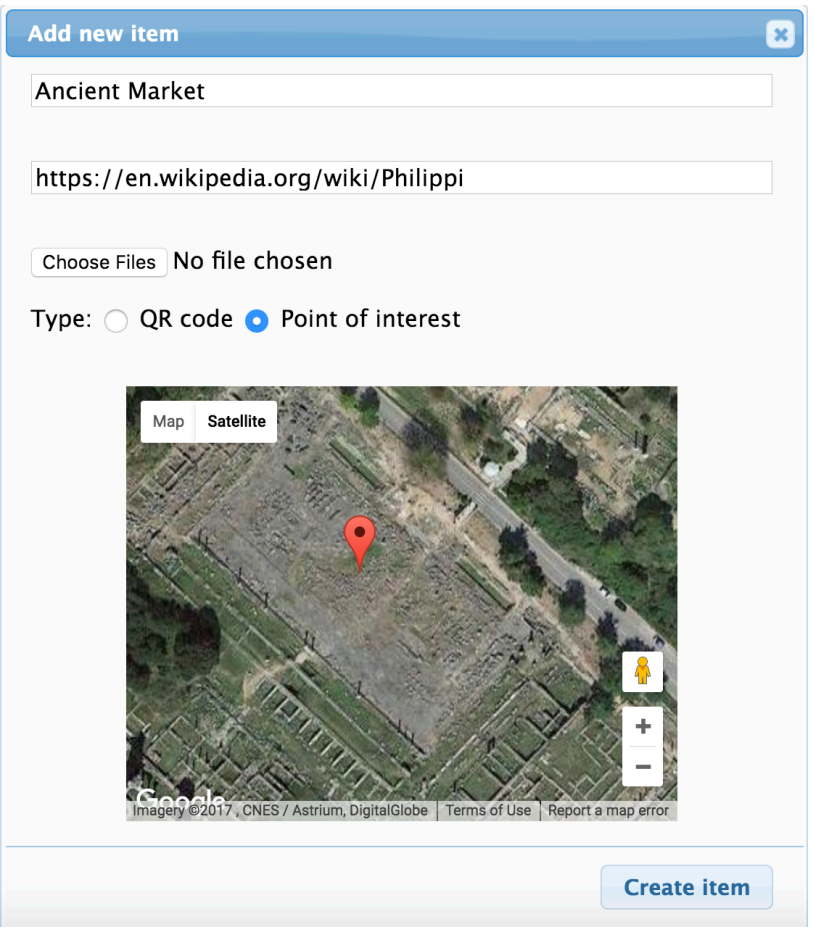

Fig. 3. Creating a new point of interest

In the case of creating $\mathrm{QR}$ items, the $\mathrm{QR}$ code is generated automatically using the relevant Google service, and the data that is coded is the unique identifier for the particular activity.

\subsection{Preparation of educational material}

One of the objectives of the mLearn platform is to allow use by educators with no special technical skills. For this reason, it has been decided that the educational material corresponding to each activity would be uploaded as a simple HTML page. Using the widely available text editing software, the teacher can prepare the educational material, and after a simple conversion the document can be saved as a single web page, with embedded any multimedia content and hyperlinks that the teacher chooses to include.

Another advantage of this approach is the compatibility of the HTML format with the mobile device operating system, which will allow displaying the HTML content using the built-in web modules, thus avoiding the use of third- party software to operate in conjunction with the mobile application. Furthermore, scripting with client-side languages such as Javascript can be easily included in order to enhance the interactivity of the content.

\section{The mobile application}

The mobile application is used by the students during the field trip to access the teacher-prepared material through investigation of the various points of interest or by scanning the QR codes depending on the type of activity.

In order to download the various data (available trips, trip activities and activity material), the application communicates with a web server which hosts the web portal and a database of trip information. A web service has been developed and installed for this purpose on the server, which ensures communication between the application and the activities database. The architecture of the system can be seen in Fig. 4.

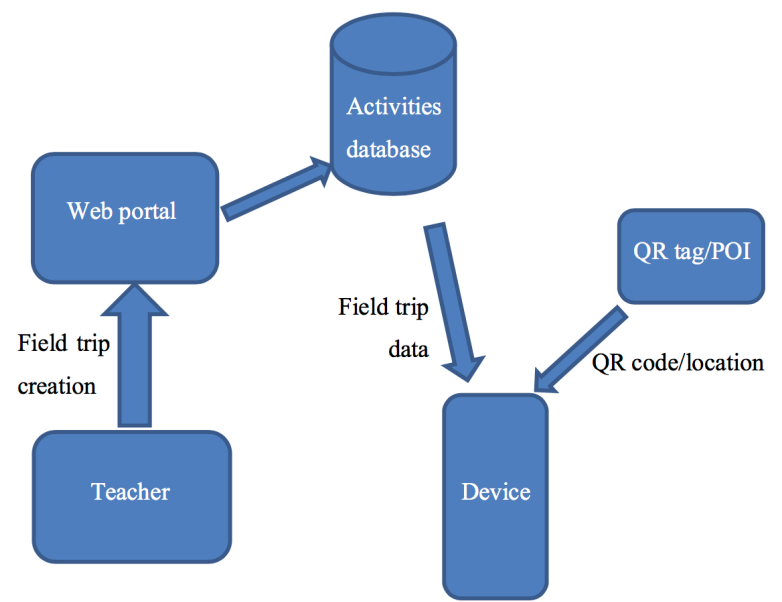

Fig. 4. Communication between mobile device and server

The application has a simple user interface in order to allow its use even by students of younger ages. When the application is opened, communication with the web server using a wireless or a GPRS network is established and the available field trips are downloaded and displayed on screen. Fig. 5 illustrates the application's first screen.

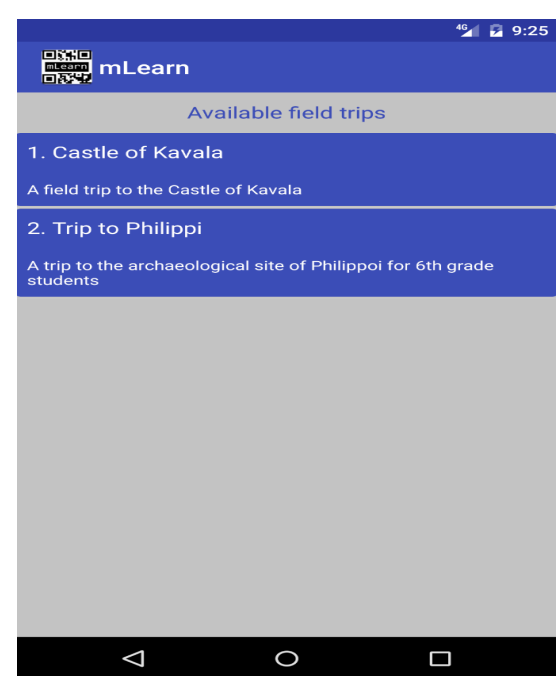

Fig. 5. Screenshot of the application's first screen 
The student can then select the field trip and and after selection, the screen of Fig. 6 is displayed. Since the activities included in a field trip can be either items accompanied by QR codes or points of interest, or a mixture of the two types of activities, the screen displays two buttons that allow access to both.

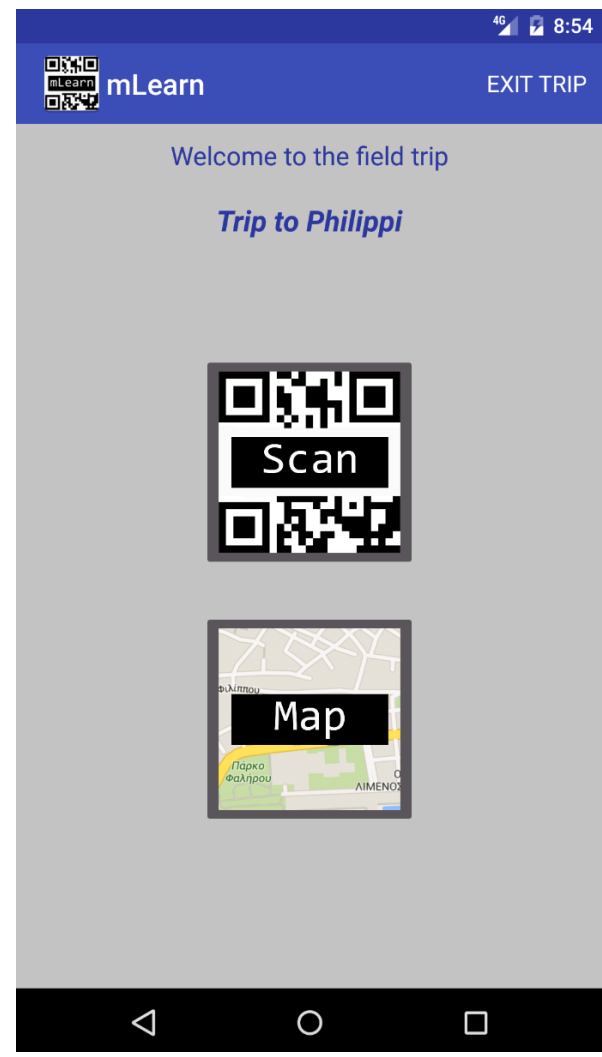

Fig. 6. Activities screen

Firstly, the Scan button leads to the QR scanning screen. QR code detection has been realized using the ZXing library, an open source barcode image processing library. The library has been incorporated into the application, so that the user remains within the application while scanning and have no need to access an external application. Fig. 7 illustrates the QR scanning screen.

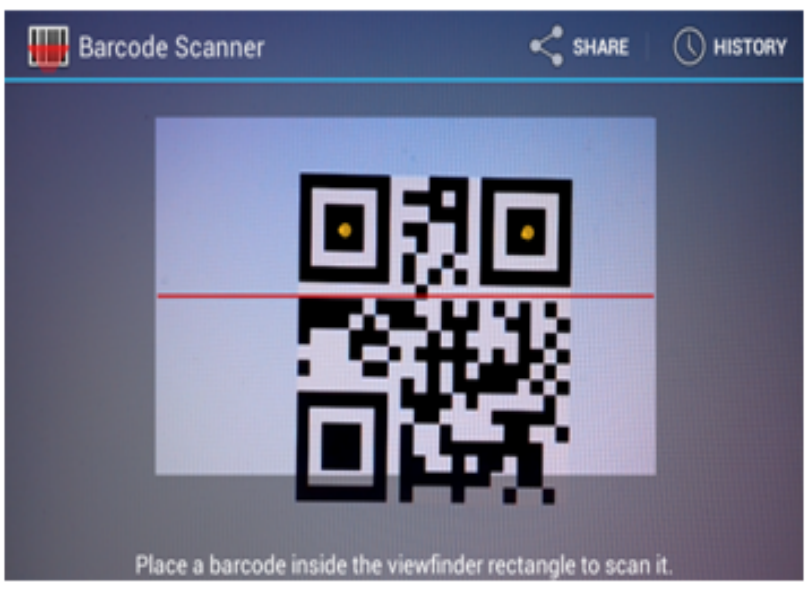

Fig. 7. QR code detection
As soon as a QR code of an item is detected by the mobile device, a request is sent to the server to fetch the content linked to the particular item, which is then displayed on the screen of the device.

In the case of points of interest, the Map button displays a map which contains the points of interest represented as markers. The map view is adjusted in such a way so that all the points of interest are displayed on screen, as shown in Fig. 8 .

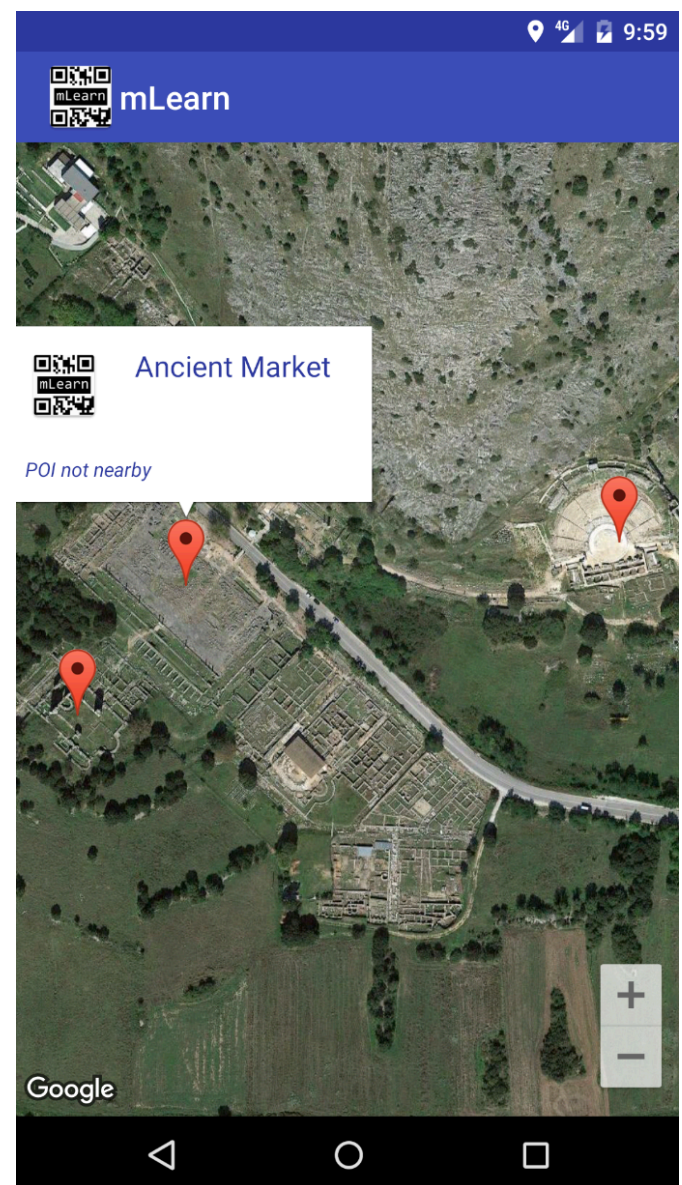

Fig. 8. Points of interest on the map

This type of view allows the student to have a clear overview of all the points of interest that he needs to visit and their relative location. When a marker is tapped, info windows about the point of interest appear on top of each map marker. Also in the bottom right hand corner the student sees buttons that help him navigate to the point of interest. Moreover, apart from the title of the point of interest, the info windows also contain an indication whether or not the user has arrived at the location. To determine whether the user is in the vicinity of a point of interest, the device's location services are activated as soon as the user selects a trip, at which time the device begins to continuously update the current location. Then, the distance between the user and the point of interest is calculated and the info windows for each marker are updated appropriately. In contrast to the screen in Fig. 8 where a point of interest not in the vicinity of the user is displayed, Fig. 9 shows how the info window of a marker is transformed when the corresponding point of interest is nearby (i.e. the user has arrived at the location). 


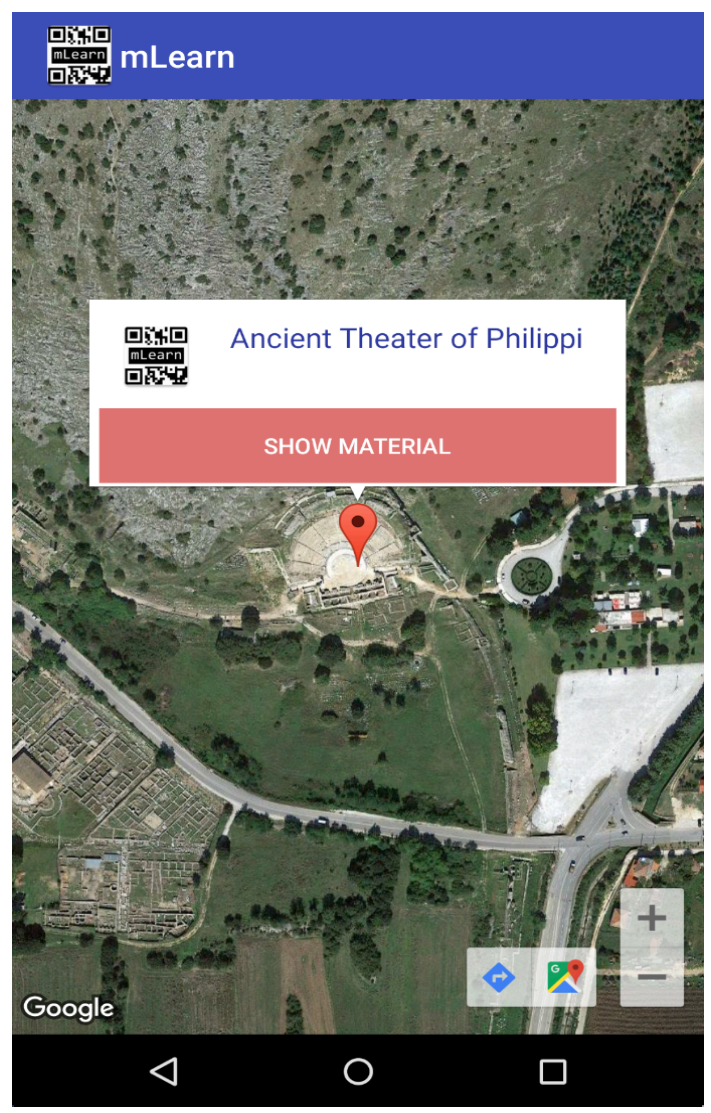

Fig. 9. Display of a nearby point of interest

It can be seen that in this case the info window now has a Show Material button, which leads to a new screen which contains the educational content prepared by the teacher for the particular point of interest (such as the screen displayed in Fig. 10). In the same fashion as with the case of $Q R$ codes, as soon as the Show material button is pressed, the corresponding material is requested and fetched from the server.

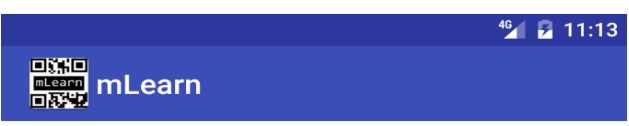

The theatre lies on the southeastern slope of the hill where the Acropolis is situated, in contact to the eastern wall of the town, where it is also supported. The older edifice with the Orchestra, whose diameter counts to $21,60 \mathrm{~m}$, dates back to the time of King Philpp W (4th century B.C.) After spectacles and the aesthetic exigencies of that period.

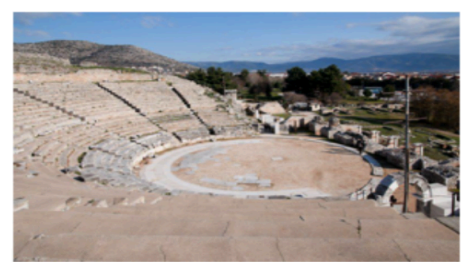

In the mid $3 r d$ century A.D. a last arrangement of the theatre was attempted, so as to create ample space for fights with wild beasts, duels attempted, so
and hunting.

That theatre constitutes an invaluable heritage for the region of Eastern Macedonia. Plenty of elements from that great theatre are still well preserved

Since, it has undergone restorations and it is suitable for hosting ancient drama performance, which are integrated in the summer programmes of Philippi and Thassos Festivals.

$\triangleleft$

O

$\square$

Fig. 10. Display of the teacher-prepared content
It is clear that in any case, the learning material is not accessible unless the student arrives on the particular location or unless he scans the QR code associated with an item, depending on the type of activity. The reason behind this design is to motivate the student to actually visit the location or view the actual item and have a situated experience while at the same time studying the accompanying content.

\section{Conclusions}

This paper proposes a mobile learning software system to aid educators to plan and conduct an educational field trip. At the current stage of development, the platform allows customized educational content to be delivered to the students, and present the relevant information on location, either by simply pointing a mobile device to a QR tag attached to an artifact or by approaching a designated point of interest. The mLearn platform offers several advantages:

- The ease of use of the web-based platform for the uploading of educational material makes it suitable for use by teachers with no technical background.

- The simple interface of the mobile application and the automated item retrieval operations (through location proximity alerts and QR code scanning) allow its use even by students of younger ages.

- In terms of the learning context, the teachers have the opportunity of creating material targeted at the educational visit and not limit themselves by the standard school textbooks. The field trips that are designed using the mLearn platform essentially follow the mobile learning paradigm, which means that self study and independent learning are promoted. The situated learning that occurs during the field trip is also a major benefit, since students are free to explore the various items or points of interest and study the material using their mobile devices at their own pace. This significantly differs from a guided tour of a location in the traditional sense.

- The realization of the educational field trips does not require specialized equipment, since the creation of material and uploading is done using conventional text editing software and a browser respectively, and conventional mobile devices are used in the actual field trip. This means that learning can be achieved at no cost.

It is intended that the open educational sources approach is adopted, which means that the material uploaded to the platform will be available to the public so that the field trips and items can be reused by teachers and students.

The next step is to test the mLearn in real educational field trip scenarios by involving local schools in the evaluation process. The purpose is initially to assess the effectiveness of the mobile learning method that is proposed as well as the usability of the web platform and application. Using the feedback from the end users (both teachers and students), it will be possible to improve the platform and adapt it to the actual educational needs of each school activity, with the 
ultimate aim of improving the quality of education through the use of the mobile learning approach.
This is an Open Access article distributed under the terms of the Creative Commons Attribution Licence

\section{References}

[1] M. Ally, "Mobile learning: transforming the delivery of education and training," Collette Qué., 2009.

[2] M. Sharples, I. Arnedillo Sánchez, M. Milrad, and G. Vavoula, Mobile Learning: Small devices, Big Issues. Book chapter to appear in Technology Enhanced Learning: Principles and Products, Kaleidoscope Legacy Book. Springer-Verlag, Berlin, 2008.

[3] C. J. Born, A. L. Nixon, and C. Tassava, "Closing in on vocabulary acquisition: The use of mobile technologies in a foreign language classroom," in Models for Interdisciplinary Mobile Learning: Delivering Information to Students, IGI Global, 2011, pp. 195-210.

[4] G. Stead, "Towards open formats for mobile learning," in 11th World Conference on Mobile and Contextual Learning, Helsinki, Finland, 2012.

[5] A. Tsinakos and M. Ally, "Global mobile learning implementation and trends," China Cent. Radio TV Univ. Press Beijing, 2013.

[6] G. Vavoula, M. Sharples, P. Rudman, J. Meek, and P. Lonsdale, "Myartspace: Design and evaluation of support for learning with multimedia phones between classrooms and museums," Comput. Educ., vol. 53, no. 2, pp. 286-299, 2009.
[7] G. Cutrí, G. Naccarato, and E. Pantano, "Mobile Cultural Heritage: the case study of Locri," in International Conference on Technologies for E-Learning and Digital Entertainment, 2008, pp. 410-420.

[8] A. I. Etxeberria, M. Asensio, N. Vicent, and J. M. Cuenca, "Mobile devices: a tool for tourism and learning at archaeological sites," Int. J. Web Based Communities, vol. 8, no. 1, pp. 57-72, 2012.

[9] F. Gonzàlez, L. Villarejo, O. Miralbell, and J. M. Gomis, "How to use mobile technology and augmented reality to enhance collaborative learning on cultural and natural heritage? An e-learning experience," in New Trends on Global Education Conference, North Cyprus, 2012.

[10]S. Ternier, R. Klemke, M. Kalz, P. Van Ulzen, and M. Specht, "ARLearn: Augmented Reality Meets Augmented Virtuality.," $J$ UCS, vol. 18, no. 15, pp. 2143-2164, 2012.

[11]C. Lytridis and A. Tsinakos, "Using a Commercial Mobile Application as a Mobile Learning Platform," in International Conference on Mobile and Contextual Learning, 2014, pp. 29-37. 